\section{Increased submucosal factor XIIla-positive dendrocytes in oral lichen planus}

Regezi JA, Daniels TE, Saeb F, Nickoloff BJ: Increased submucosal factor XIIIapositive dendrocytes in oral lichen planus. J Oral Pathol Med 1994; 23: 1148. C Munksgaard, 1994 .

Factor XIIIa + "dendrocytes", normal residents of the submucosa and dermis, are a morphologically and phenotypically distinctive subset of the monocytemacrophage system. Because these cells are believed to participate in the regulation of immune responses, we postulated that they may play a role in the pathogenesis of lichen planus, a condition of immune dysregulation. Tissue sections of oral lichen planus were evaluated immunohistochemically for evidence of differences in dendrocyte populations in lesional and non-lesional areas from the same patient. In addition to factor XIIIa, sections were stained for antigens (CD68, S-100 protein, CD36) that may be expressed by other cells that occasionally exhibit dendritic profiles. CD18 (found on leukocytes and dendrocytes) and its ligand ICAM-1 (intercellular adhesion molecule) were also identified in sections to determine if these antigens are operative in lichen planus. Results showed that XIIIa + dendrocytes were significantly increased in number (and size) in lichen planus. The mean number of dendrocytes in connective tissue subjacent to basement membrane $\left(0.064 \mathrm{~mm}^{2}\right)$ was 27 in lichen planus as compared to 10 in adjacent unaffected tissue. Similar increases were also evident in connective tissue deep to this zone (mean of 20 dendrocytes vs. mean of 8). CD68+ macrophages were also abundant in the lichen planus infiltrate, and $\mathrm{S}-100+$ connective tissue cells were frequently seen. CD36 + dendritic cells were seen in relatively small numbers in the same sites where dendrocytes were found. ICAM-1 + connective tissue dendritic cells of undetermined lineage were also evident in the diseased areas. Endothelial cells in and around the infiltrate were strongly reactive to antiICAM-1. Basal and parabasal keratinocytes overlying the lymphoid infiltrates were also strongly ICAM-1 +. It appears that XIIIa + dendrocytes have a role in the immunologic mechanisms of lichen planus, and that these cells may be acting in concert with other immunocompetent cells, such as macrophages and S$100+$ epithelial dendritic cells, to activate T lymphocytes. ICAM-1 expression by dendrocytes, endothelial cells, and keratinocytes may facilitate leukocyte migration to, and retention in. the disease focus.
Joseph A. Regezi ${ }^{1}$, Troy E. Daniels ${ }^{1}$, Farah Saeb' ${ }^{1}$ and Brian J. Nickoloff ${ }^{2}$ 'Division of Oral Pathology, School of Dentistry, University of California, San Francisco, ${ }^{2}$ Department of Pathology, School of Medicine, University of Michigan. Ann Arbor, USA
Key words: CD36; CD68; dendrocytes; factor XIIla: ICAM-1; immunohistochemistry: LFA; lichen planus: macrophages: oral: S-100 protein.

Joseph A. Regezi, Oral Pathology, Dept. of Stomatology, University of California, SF. S-512, San Francisco, CA 94143-0424, USA

Accepted for publication September 3, 1993
Macrophage-related factor XIIIa-positive dendrocytes are normal residents of the dermis and submucosa (1-3). Their dendritic profiles become evident when stained for blood group factor XIIIa, an enzyme that has a role in fibrin stabilization and possibly also in extracellular matrix production and fibroblast proliferation $(4-7)$. These cells are particularly prominent around blood ves- sels, especially in the lamina propria, and between collagen bundles.

Dendrocytes share many antigenic determinants with monocyte-macrophages, such as $\mathrm{CD} 4+, \mathrm{CDIlb}+$, CDI4+, CDI8+, and CD45+. Their morphology and expression of HLADR suggest that they are capable of processing and presenting antigens (7-10). Using isolated dermal dendro- cytes, it has been recently shown that these cells are potent stimulators of resting $T$ cells $(11,12)$. It is believed that the prominent position of dendrocytes in connective tissue papillae and perivascular spaces makes them uniquely capable of monitoring antigens appearing in the external and internal environments. It is also believed that they influence lymphocyte movement in tissue via 
the liberation of tumor necrosis factor, a substance which induces ICAM-1 (intercellular adhesion molecule) expression on endothelial cells and keratinocytes (13-15).

Lichen planus, a relatively common chronic mucocutaneous disease of unknown cause, is generally considered to be an immunologically-mediated process that microscopically resembles a hypersensitivity reaction. The disease mechanism has not been fully explained, although basal keratinocytes appear to be the targets for activated T-lymphocytes $(16,17)$. The adhesion molecule ICAM-1, which helps regulate lymphocyte traffic in extravascular compartments, may also be important in the pathogenesis of lichen planus. In one study, keratinocytes in lichen planus consistently expressed ICAM-1 (18), while in another expression was inconsistent (19). In a study in which cyclosporin was used to treat oral lichen planus, ICAM-1 was expressed by keratinocytes before treatment, but was undetectable after therapy (20).

Because of the prevalence of factor $\mathrm{XIIIa}+$ dendrocytes in oral mucous membranes, and because of their apparent role in $\mathrm{T}$ cell immune reactions, we propose that these cells may be involved in the pathogenesis of oral lichen planus. In a recent study of cutaneous lichen planus, both dendrocytes and macrophages were increased in numbers in active lesions (21). The purpose of this investigation was to determine the prevalence and distribution of factor $\mathrm{XIIIa}+$ dendrocytes in oral lichen planus. Immunohistochemical stains identifying other connective tissue dendritic cells $(\mathrm{KPl}+$ macrophages, S-100 + preLangerhans cells, CD36+ dendritic cells [22]) were also done for comparison. Further, sections were stained for CD18, leukocyte function antigen, and vance of these antigens with regard to expression on dendritic cells in the pathogenesis of lichen planus.

\section{Material and methods}

From the oral pathology biopsy service, 16 formalin-fixed paraffin-embedded tissue specimens (mean patient age of $57 \mathrm{yr}$ and range of 36-76 yr), and 16 frozen tissue specimens (from 16 different patients, mean age of $55 \mathrm{yr}$ and range of 33-77 yr) of oral lichen planus were selected for this study. All 32 specimens were from patients with the clinical diagnosis of lichen planus, and all lesions were of the reticular type from the buccal mucosa. The histologic criteria that had to be met for inclusion in the study were hyperkeratosis, basal layer vacuolation, and a lymphocyte/ macrophage infiltrate located at the epithelial-connective tissue interface.

Formalin-fixed, paraffin-embedded tissue sections were utilized for demon- strating cells expressing factor XIIIa, S100 protein, and CD68 (KP1) (Table 1). Sections were mounted on adhesive coated glass slides for immunohistochemical staining. Antibodies to factor XIIIa, S-100 protein, and CD68 were applied to dewaxed formalin-fixed sections. Sections were digested with $0.4 \%$ pepsin (Sigma Chemical Co., St Louis, MO) and incubated overnight at $4^{\circ} \mathrm{C}$ with primary antibody. Subsequent incubations were with biotinylated IgG followed by avidin-biotin peroxidase complex (Vectastain, Vector Laboratory, Burlingame, CA). Sections were developed in aminoethylcarbazole and counterstained with Mayer's hematoxylin. Negative controls consisted of substitution of primary antibody with normal rabbit serum or mouse serum. Cryostat sections were used to demonstrate CD36 + (OKM5) dendritic cells, CD18 + cells, and ICAM-1 expression. Sections were air dried and fixed in acetone at $4^{\circ}$ centigrade for 10 minutes. The above avidin-biotin-peroxidase technique was used to identify these fixation-sensitive antigens.

A $10 \times 10$ ocular graticule outlining an area of $0.064 \mathrm{~mm}^{2}$ was used at a magnification of $400 \times$ to assist in counting cells in sections stained for factor XIIIa, CD68, S-100 protein, CD36, CDI8, and ICAM-1. The grid was positioned parallel to the epithelial-connective tissue interface, outlining an area that extended from the basement mem-

Table 1. Antibodies used in this study.

\begin{tabular}{|c|c|c|c|c|}
\hline Antibody (class) & Antigen & Cells stained & Dilution & Source \\
\hline anti-factor XIIIa (polyclonal) & coagulation factor XIIIa & dendrocytes $(23)$ & $1: 1500$ & Calbiochem, La Jolla, CA \\
\hline anti-S-100 (polyclonal) & S-100 protein & (pre) Langerhans cells (24) & $1: 2500$ & Dako, Santa Barbara, CA \\
\hline KPI (IgGI) & CD68 & macrophages $(25)$ & $1: 50$ & Dako, Santa Barbara, CA \\
\hline OKMS (IgG1) & CD36 & $\begin{array}{l}\text { macrophages \& dendritic cells } \\
\text { (22) }\end{array}$ & $1: 500$ & Ortho, Raritan, NJ \\
\hline anti-CD18 (IgG1) & $\begin{array}{l}\text { CD18 (leukocyte function } \\
\text { antigen) }\end{array}$ & leukocytes $(26)$ & $1: 500$ & Dako, Santa Barbara, CA \\
\hline anti-ICAM-1 (IgG1) & $\begin{array}{l}\text { antigen) } \\
\text { intercellular adhesion molecule }\end{array}$ & endothelial cells (26) & $1: 10,000$ & $\begin{array}{l}\text { R \& D Systems, Minneapolis, } \\
\text { MN }\end{array}$ \\
\hline
\end{tabular}

Table 2. Cell-associated antigen expression in submucosa of oral lichen planus $(n=16)$

\begin{tabular}{|c|c|c|c|c|c|c|}
\hline & \multicolumn{6}{|c|}{ Antigen expressed } \\
\hline & XIIIa & CD68 & S-100 & CD36 & CD18 & ICAM-1 \\
\hline Lichen planus - level I & $* 27(5.5)$ & $29(9.8)$ & $10(3.0)$ & $10(5.1)$ & $250(26)$ & $10(6.1)$ \\
\hline Lichen planus - level 2 & $* * 20(6.2)$ & $14(9.2)$ & $2(0.9)$ & $4(3.8)$ & $38(25)$ & $9(7.2)$ \\
\hline Unaffected site - level 1 & $10(6.4)$ & $7(6.3)$ & $1(0.8)$ & $2(1.8)^{+}$ & $15(2.7)^{+}$ & 0 \\
\hline Unaffected site - level 2 & $8(4.0)$ & $5(3.9)$ & 0 & $2(1.3)^{+}$ & $4(1.2)^{+}$ & 0 \\
\hline
\end{tabular}

* Mean number of positively stained cells in connective tissue area $\left(0.064 \mathrm{~mm}^{2}\right)$ subjacent to basement membrane. Standard deviation in parenthesis.

** Mean number of positive cells in connective tissue $\left(0.064 \mathrm{~mm}^{2}\right)$ deep to level 1 - (counts do not include endothelial cells stained with antiCD36 and anti-ICAM).

$n=6$ 


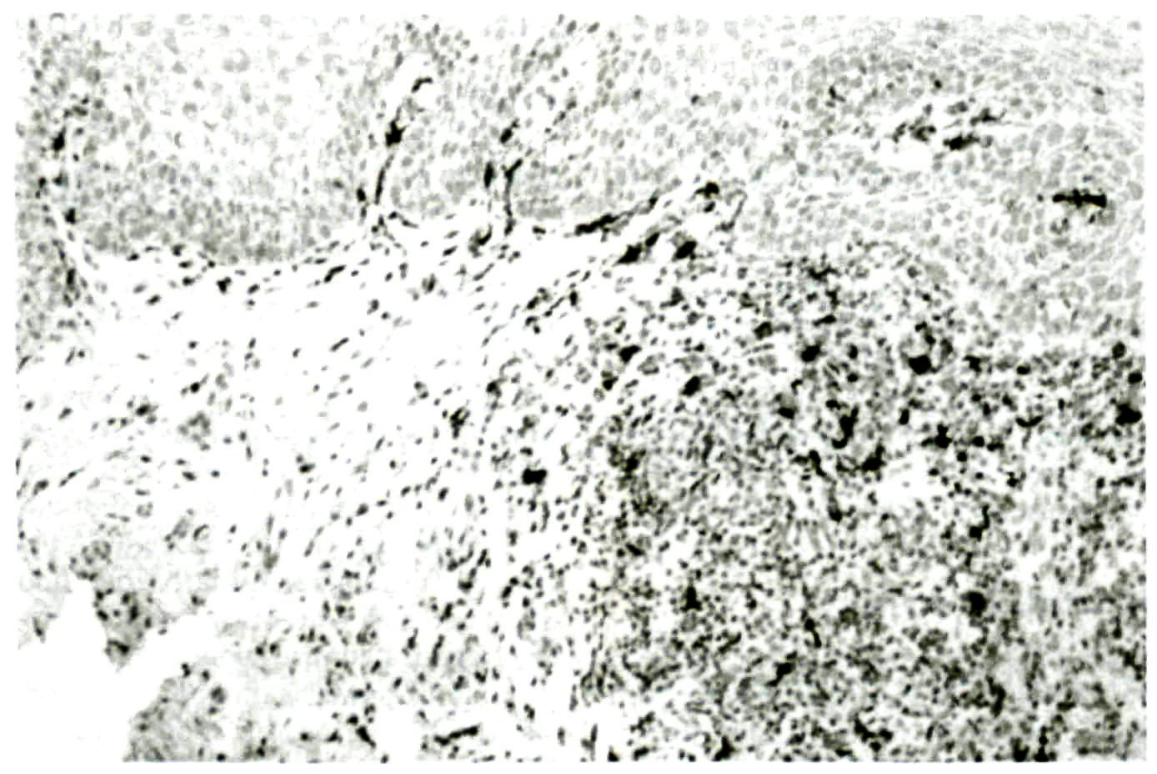

Fig. 1. Factor XIIIa immunohistochemical stain of lichen planus (right) adjacent to unaffected tissue (left). Darkly stained dendrocytes can be seen scattered among the cellular infiltrate and in the connective tissue papillae (Hematoxylin counterstain, $\times 100$ ).

brane to a depth of $0.064 \mathrm{~mm}$ (level 1). Positively stained cells were counted within the outlined area, as well as in an additional $0.064 \mathrm{~mm}^{2}$ area of connective tissue deep to the first (level 2). Only cells with nuclei were included. Counts from five adjacent high-power fields in a single section were averaged. Histologically unaffected tissue adjacent to the diseased zones (showing no hyperkeratosis, basal layer vacuolation, or significant lymphocytic infiltration) were used for comparison. Differences in cell counts in affected and unaffected "control" sites were statistically evaluated using the paired t-test.

\section{Results}

$\mathrm{XIIIa}+$ dendrocytes were significantly increased in number in both levels 1 and 2 in lichen planus as compared to adjacent unaffected "control" areas $(P<0.00001)$ (Table 2$)$. They were also subjectively increased in size (Figs 1-3). These factor XIIIa-positive dendrocytes

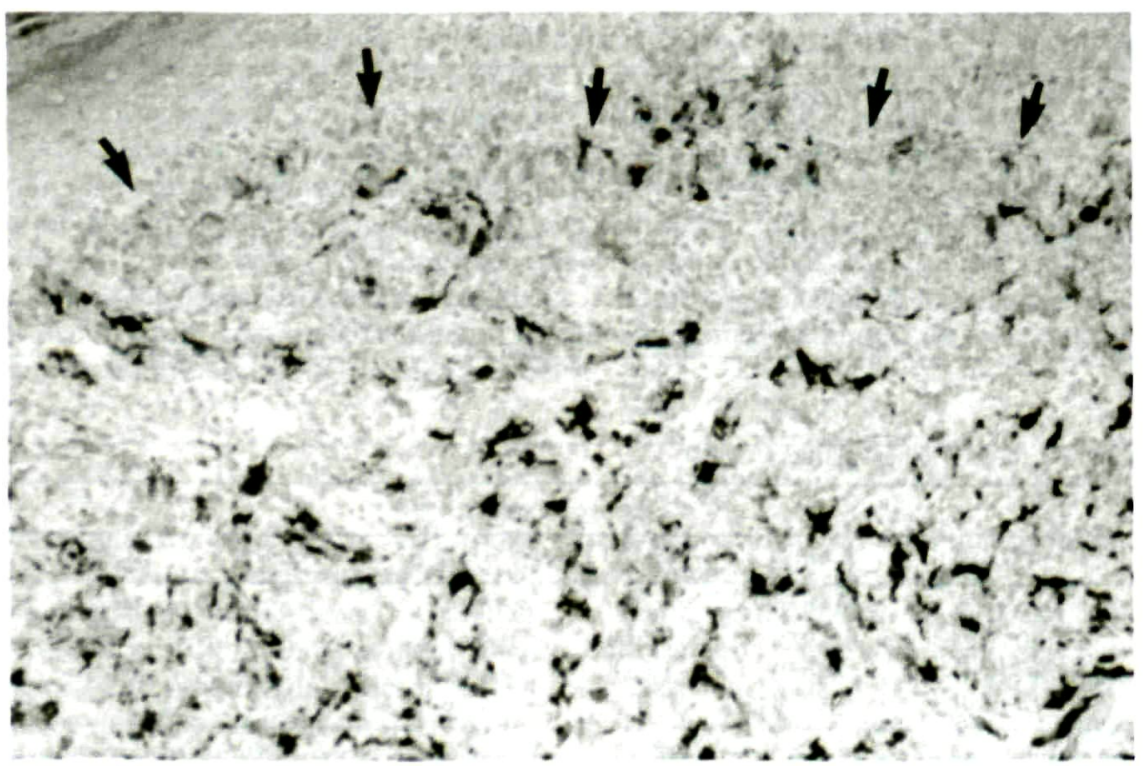

Fig. 2. Factor XIIla immunohistochemical stain of the submucosal infiltrate in oral lichen planus. Epithelial-submucosal interface can be seen top (arrows). Dark cells are factor XIIIa + dendrocytes. Nuclei of the remainder of the infiltrate are lightly counterstained with hematoxylin $(\times 100)$. were distributed throughout the lymphocyte infiltrate. Frequently, dendrocytes were concentrated in the lamina propria and in the connective tissue directly subjacent to the lymphocytic infiltrate.

$\mathrm{CD} 68+$ macrophages were seen in significantly greater numbers in both levels 1 and 2 as compared to adjacent unaffected sites $(P<0.00001)$. In level 1 connective tissue, CD68 + macrophages were seen in numbers that approximated to those of the XIIIa+ dendrocytes. The morphology of the macrophages was predominately round to oval with occasional dendritic profiles noted. In level 2, cells were notably less numerous, with more dendritic and spindle shapes being seen.

$\mathrm{S}-100+$ connective tissue cells were also significantly increased in number in the submucosa of the diseased tissue as compared to the unaffected adjacent tissue $(P<0.00001)$. Cell morphology was typically oval or polygonal. Dendritic processes were often seen extending from the cell body.

CD36 + dendritic cells were occasionally seen in unaffected submucosa adjacent to lichen planus. These cells were only somewhat more frequent in diseased tissue (level $1-P<0.02$, level 2 - not significant). Endothelial cells were typically CD36+, though occasional non-reactive vessels were found distant to the inflammatory focus. In nine cases, keratinocytes overlying the inflammatory cell infiltrate were CD36+

Intense CD18 staining of the lichen planus cellular infiltrate was noted in all cases. The percent of positive cells (lymphocytes, macrophages, and dendritic cells) in the infiltrate ranged from 75 to $90 \%$. Intraepithelial dendritic cells, presumably Langerhans cells, also stained with this antibody.

All endothelial cells were ICAM-1+. Subjectively, capillaries around the cellular infiltrates were more intensely stained than those distant to them. Positive-staining spindle and dendritic connective tissue cells were evident in the area of the infiltrate, but not in the unaffected adjacent tissue. In all cases, basal and parabasal keratinocytes expressed ICAM-1 positivity, though intensity was somewhat variable. Normal appearing epithelium adjacent to diseased tissue was ICAM-1 negative.

\section{Discussion}

It is apparent that XIIIa+ dendrocytes make up a significant part of the submu- 


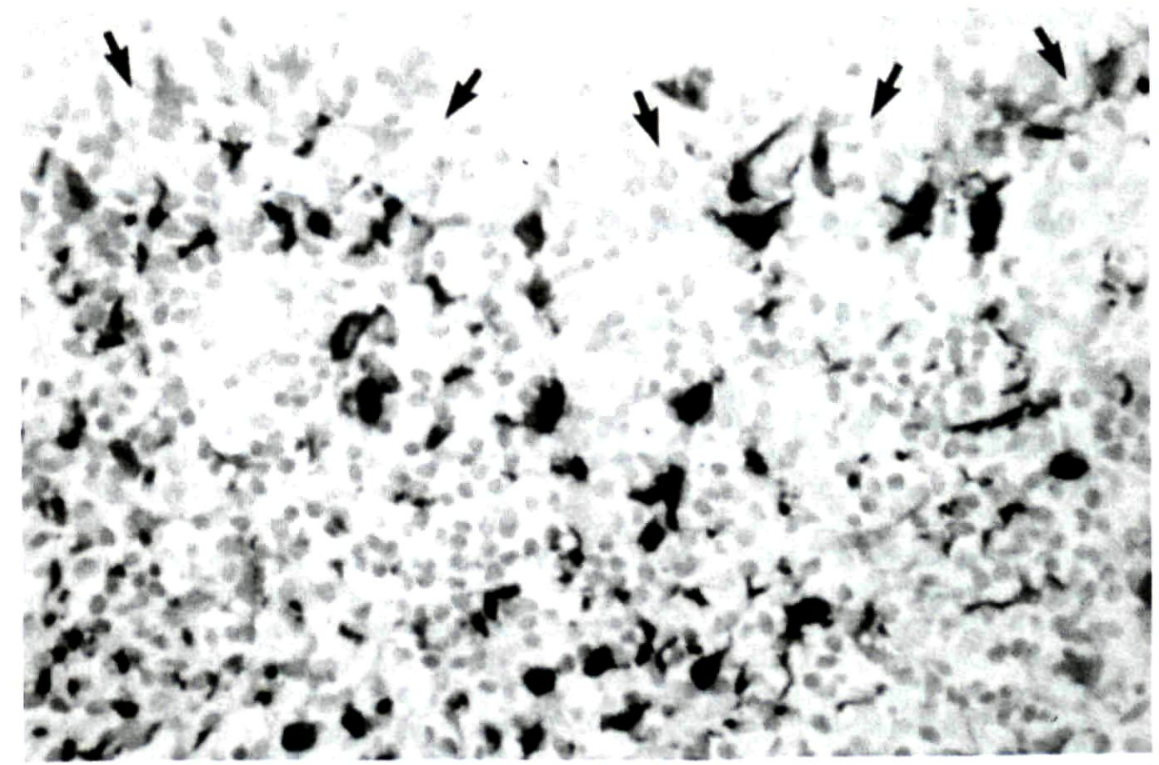

Fig. 3. Higher magnification of factor XIIIa immunohistochemical stain of the submucosal infiltrate in oral lichen planus. Epithelial-submucosal interface at top (arrows). Dark staining cells are factor XIIIa + dendrocytes (Hematoxylin counterstain, $\times 250$ ).

cosal cell population in lichen planus. Because it is believed that these cells participate in immune responses, it likely that they play a role in this immunologically mediated disease. Antigen processing and presentation would be the expected role for dendrocytes. This would be similar to the expected roles played by the CD68+ macrophages and S-100+ cells identified in the submucosa of the cases studied. Macrophages would also have a phagocytic function in this disease, since there is significant basal cell necrosis in lichen planus.

It should be noted that increased numbers of XIIIa + dendrocytes are not specific or unique for lichen planus. Significant numbers have been documented in other oral reactive and neoplastic lesions $(27,28)$. It has been postulated that dendrocytes in these diverse lesions are involved in the immune/inflammatory response as well as in the reparative process (fibroplasia).

Since the frozen specimens and paraffin-embedded specimens were from two different patient pools, direct comparison of results between fixation-sensitive antigens (ICAM, CD18, CD36) and formalin-resistant antigens (XIIIa, CD68. S-100) was not made. Nonetheless, it appears that ICAM-I may be one of the factors that is responsible for cell recruitment and retention in this disease. One could speculate that cells expressing its ligand, CDI8, could move from the vascular compartment to the interstitial spaces, and then to the ICAM-1-positive keratinocytes where cytotoxicity can be effected. Dendrocytes, believed to produce tumor necrosis factor (29), may be partly responsible for the autocrine and paracrine induction of ICAM-1 expression through the release of this cytokine. Dendrocytes may then help control lymphocyte traffic in lichen planus through tumor necrosis factor-induced ICAM-1 on endothelial cells and keratinocytes.

CD36, an antigen that may be expressed by monocyte-macrophages, also identifies a subset of dendritic cells in the subepithelial and perivascular tissues of mucous membrane and skin (22). It has not been determined whether these cells are identical to factor XIIIaexpressing dendrocytes, or whether they are a distinctive macrophage subset. Based on cell morphology and distribution. the CD36-expressing (OKM5+) cells in lichen planus could be dendrocytes. Induction of CD36 on keratinocytes has been described following gamma interferon stimulation $(30,31)$. That nine cases in this study showed CD36 expression by keratinocytes suggests that gamma interferon (from the infiltrating lymphocytes) may be important in this disease.

We conclude that there is a significant and distinctive factor XIIIa + dendrocyte population in the submucosa of oral lichen planus. These dendrocytes. which are believed to play a role in anti- gen processing, may be acting in concert with other immunocompetent cells, such as macrophages and S-100+ connective tissue and epithelial cells (Langerhans cells) to mediate this disease. ICAM-1 expression by endothelial cells. dendrocytes, and keratinocytes appears to be an important mediator of lichen planus.

Acknowledgement - Research supported by UCSF Senate Grant 2-509737-35488.

\section{References}

1. Cerio R, Griffiths C, Cooper K. NickOLOFF B. HeAdington JT. Chacterization of factor XIIIa positive dermal dendritic cells in normal and inflamed skin. British J Dermatol 1989: 121: 421-31.

2. Nickoloff B, Griffiths C. Not all spindle-shaped cells embedded in a collagenous stroma are fibroblasts: recognition of the "collagen-associated dendrophage". J Cutan Pathol 1990: 17: 252-3.

3. Regezi JA, Nickoloff BJ. Headington JT. Oral submucosal dendrocytes: factor XIIIa and CD34 dendritic cell populations in normal tissue and fibrovascular lesions. J Cutan Pathol 1992: 19 . $398-406$

4. Fear J. Jackson P. Gray C. MiloszewSKI K. LOsowsKI R. Localization of factor XIII in human tissues using an immunoperoxidase technique. $J$ Clin Pathol 1984: 37: $560-3$.

5. Henriksson P. Becker S, Lynch G. McDoNaGH J. Identification of intracellular factor XIII in human monocytes and macrophages. I Clin Invest 1985: 76: 528-34.

6. Muszber L. Adany R, Szzeged G. Polgar J, Kaval M. Factor Xill of blood coagulation in human monocytes. Thrombosis Res 1985: 37: 401-10.

7. Reid M. Gray C. Fear J. Bird C. Immunohistological demonstration of factors XIIIa and XIIIs in reactive and neoplastic fibroblastic and fibro-histiocytic lesions. Histopathol 1986; 10: 1171-8.

8. Cerio R. Spaull J. Oliner G. WilsonJONES E. A study of factor XIIIa and MAC 387 immunolabeling in normal and pathological skin. Am J Dermatopathol 1990: 12: 221-33.

9. Steinman R, Nussenzweig M. Dendritic cells: features and functions. Immunological Rev 1980: 53: 12746.

10. Wood G. Turner R. Shiurba R. ENG L. WARNKE R. Human dendritic cells and macrophages. Am J Pathol 1985; 119 $73-82$.

11. Nestle F, Turka L. Nickoloff BJ. Purification and immunological characterization of dermal dendrocytes obtained from normal skin. I Invest Dermatol 1993: 100: 521 (abstract)

12. Nestle F. Turka L. Nickoloff BJ Comparative functional analysis of den- 


\section{Regezi et al.}

dritic cells obtained from human epidermis (Langerhans cells), dermis (dermal dendrocytes), and peripheral blood. $J$ Invest Dermatol 1993; 100: 562 (abstract).

13. Nickoloff B, Griffiths C, Barker J. The role of adhesion molecules, chemotactic factors, and cytokines in inflammatory and neoplastic skin disease. $J$ Invest Dermatol 1990; 94: 151-157S.

14. Nickoloff B, Karabin G, Barker J, et al. Cellular localization of interleukin-8 and its inducer, tumor necrosis factoralpha in psoriasis. Am J Pathol 1991; 138: $129-40$

15. Nickoloff B, Griffiths C. Abnormal cutaneous topobiology: the molecular basis for dermatopathic mononuclear cell patterns in inflammatory skin disease. J Invest Dermatol 1990; 95: 128-31S.

16. Gilmar A, Pillar T, Winterstein G, EtZIONI A. The pathogenesis of lichen planus. Br J Dermatol 1989; 120: $541-4$.

17. Bolsnic S, Frances C. Branchet M. SzPIRGlas H, Char PENTIER Y. Immunohistochemical study of oral lesions of lichen planus: diagnostic and pathophysiologic aspects. Oral Surg Oral Med Oral Pathol 1990; 70: 462-5.

18. Konter U, Kellner I. Hoffmeister B. STERRY W. Induction and upregulation of adhesion receptors in oral and dermal lichen planus. J Oral Pathol Med 1990: 19: $459-63$.
19. Verdickt GM, Savage NW, Dodd NM, WALSH L J. Expression of the CD54 (ICAM) and CD11a (LFA-1) adhesion molecules in oral mucosal inflammation. J Oral Pathol Med 1992; 21: 65-9.

20. Eisen D, Griffiths CEM, Ellis CN, NiCkoloff BJ, VoORHEES JJ. Cyclosporin wash for oral lichen planus. Lancet 1990 ; 335: 535-6.

21. Akasu R, From L, Kahn HJ. Lymphocyte and macrophage subsets in active and inactive lesions of lichen planus. $\mathrm{Am}$ J Dermatopathol 1993; 15: 217-23.

22. Pimpinelli N, Borgognoni L, Riccardi R, Ficarra G, Gaglioti D, Romagnoli P. CD36 (OKM5)+ dendritic cells in the oral mucosa of HIV- and HIV + subjects. J Invest Dermatol 1991; 97: 537-42.

23. Cerio R, Griffiths C, Cooper K, NickoLOFF B, HeAdington JT. Characterization of factor XIIIa positive dendritic cells in normal and inflamed skin. Br J Dermatol 1989; 121: 421-31.

24. TAKAHASKI K, IsOBE T, OHTSUKI Y, SONOBE H, TAKEDA I, AKaGi T. Immunohistochemical localization and distribution of $\mathrm{S}-100$ proteins in the human lymphoreticular system. Am J Pathol 1984; 116 497-503.

25. Pulford KAF, Rigney EM, Micklem $\mathrm{KJ}$,et al. A new monoclonal antibody that detects a monocyte/macrophage associ- ated antigen in routinely processed tissue sections. J Clin Pathol 1988; 42: 414-21.

26. SPringer TA. Adhesion molecules of the immune system. Nature 1990; 346: 425-34.

27. Regezi JA, Zarbo RJ, Daniels te, GREENSPAN JS. Oral traumatic granuloma: characterization of the cellular infiltrate. Oral Surg Oral Med Oral Pathol 1993; 75: 723-7.

28. Regezi JA, Nickoloff BJ, HeAdington JT. Oral submucosal dendrocytes: factor $\mathrm{XIIIa}+$ and CD34 + dendritic cell populations in normal tissue and fibrovascular lesions. J Cutan Pathol 1992; 19: 398406.

29. Nickoloff BJ, Karabin GD, Barker JNWN, et al. Cellular localization of interleukin-8 and its inducer, tumor necrosis factor-alpha in psoriasis. Am J Pathol 1991; 138: 129-40.

30. Hunyadi J, Simon M. Expression of OKM5 antigen on human keratinocytes in vitro upon stimulation with gammainterferon. Acta Derm Venerol (Stockh) 1986; 66: 527-30.

31. Simon M, Hunyadi J. Expression of OKM5 antigen on human keratinocytes in positive intracutaneous tests for delayed-type hypersensitivity. Dermatologica 1987; 175: 121-5. 
This document is a scanned copy of a printed document. No warranty is given about the accuracy of the copy. Users should refer to the original published version of the material. 